International Journal of Social Science And Human Research

ISSN(print): 2644-0679, ISSN(online): 2644-0695

Volume 04 Issue 12 December 2021

DOI: $10.47191 / \mathrm{ijsshr} / \mathrm{v} 4-\mathrm{i} 12-71$, Impact factor-5.586

Page No: 3964-3969

\title{
How the Lack of a Universal Definition of Childhood Neglect is Negatively Impacting U.S. Families
}

\author{
Michelle Hogan', Victor Harris, Ph.D. ${ }^{2}$ \\ ${ }^{1}$ University of Florida \\ ${ }^{2}$ CFLE University of Florida
}

\begin{abstract}
Social Judgment Theory can be a useful tool in understanding the ways in which judgment plays a role in how Child Protective Investigators determine if a child has been neglected. In most States, more children are removed by charges of 'neglect only' than for any other reason. A close examination of the States' definitions of childhood neglect may offer insight as to how the writing of laws allows for discernment among case workers and further how their judgment is impacted by their own personal beliefs. In an effort to ensure child safety and prevent future traumas, the utilization of Social Judgment Theory should be considered in the social and psychological research of child welfare. Varying definitions of how neglect may propose a new variable in the differing outcomes of child removal between the states are discussed.
\end{abstract}

KEYWORDS: Social Judgment Theory, Child Welfare, Child Neglect

\section{INTRODUCTION}

\subsection{Introduction of the Problem}

In 2018, 163,543 children were removed from their homes from child welfare services by reason of neglect only. 'Neglect only' means that there were no other coinciding occurrences such as drug abuse, physical abuse, parent incarceration, or any other cause of concern for a child's safety. Neglect only makes up $62 \%$ of all child removals combined in the United States. Trailing far behind is drug abuse by the parent (36\%), caretaker inability to cope (14\%), physical abuse (13\%), inadequate housing (10\%), child behavior problems (9\%), parent incarceration (7\%), alcohol abuse by the parent ( $5 \%)$, abandonment ( $5 \%)$, sexual abuse (4\%), child drug abuse (2\%), child disability ( $2 \%$ ), relinquishment (1\%), parent death ( $1 \%$ ) and finally, child alcohol abuse (0\%) ( U.S. Department of Health and Human Services, Administration for Children and Families, Administration on Children, Youth and Families, Children's Bureau, 2019). It is important to examine how vast the difference is in the amount of neglect only cases compared with all of the other types of reasons for child removal. This differential raises the question if child neglect is this biggest issue occurring among American families or if there are other contributing factors that may account for this disparity. This paper seeks to explore how the actual definition of neglect may be one of those contributing factors.

\subsection{Literature Review : Selected States' Definitions of Child Neglect and Number of Cases}

Child welfare is governed at the state level, rather than federal. In all states except for Alabama, the preponderance of cases for state involvement were for neglect only. In a majority of the states, neglect only cases comprise more than half of all of their reported child welfare cases. Some state's reports are as high as $80 \%$ or more, such as Montana with $92 \%$. The states with the highest numbers of neglect only cases were California, New York and Texas (U.S. Department of Health and Human Services, Administration for Children and Families, Administration on Children, Youth and Families, Children's Bureau, 2019) (USDHHS). It is critical to not only look at the states with the highest number of cases, but to also consider this relationship relative to child population size. By calculating the number of neglect cases with the number of children in that state, it's possible to determine which states had the highest average relevant cases according to their child population. The states with the highest averages were California, Florida and Texas. The states with the overall lowest averages were Vermont and Hawaii. Below, the states with the highest and the lowest pertinent cases and their corresponding definitions of neglect will be examined.

California. A full 77.8\% of maltreatment cases in California are for neglect only, which represents nearly all of the cases. In total, there were 49,633 cases. The child population is about 8.7 million (U.S. Census Bureau, 2019), therefore, given the current numbers it can be estimated that $1.7 \%$ of children will be involved in a neglect case with the department of children's services during any given year. Additionally, $87 \%$ of children in foster care have entered the system due to neglect only reasons (USDHHS), 2019). Below, is the definition of child neglect in California: 


\section{How the Lack of a Universal Definition of Childhood Neglect is Negatively Impacting U.S. Families}

A child may be considered dependent under the following circumstances:

- The child has suffered, or there is a substantial risk that the child will suffer, serious physical harm or illness as a result of the following:

${ }^{\circ}$ The failure or inability of the parent or guardian to adequately supervise or protect the child.

- The willful or negligent failure of the parent or guardian to adequately supervise or protect the child from the conduct of the custodian with whom the child has been left.

${ }^{\circ}$ The willful or negligent failure of the parent or guardian to provide the child with adequate food, clothing, shelter, or medical treatment.

${ }^{\circ}$ The inability of the parent or guardian to provide regular care for the child due to the parent's or guardian's mental illness, developmental disability, or substance abuse.

- The child's sibling has been abused or neglected, and there is a substantial risk that the child will be abused or neglected. The court shall consider the circumstances surrounding the abuse or neglect of the sibling, the age and gender of each child, the nature of the abuse or neglect of the sibling, the mental condition of the parent or guardian (Children's Bureau Child Welfare Information Gateway, 2019).

Texas. Approximately $75.2 \%$ of all maltreatment cases in Texas are due to neglect only. Similar to California, this percentage of neglect only cases encompasses almost all of the maltreatment cases. This tallies up to 47,592 cases (USDHHS), 2019). The child population in Texas is approximately 7.2 million (U.S. Census Bureau, 2019), which means that about $1.5 \%$ of the child population each year will likely be subjected to a neglect case that may constitute family separation. The following is the legal definition of neglect in Texas:

(4) "Neglect":

(A) includes:

(I.) the leaving of a child in a situation where the child would be exposed to a substantial risk of physical or mental harm, without arranging for necessary care for the child, and the demonstration of an intent not to return by a parent, guardian, or managing or possessory conservator of the child;

(ii) the following acts or omissions by a person:

(a) placing a child in or failing to remove a child from a situation that a reasonable person would realize requires judgment or actions beyond the child's level of maturity, physical condition, or mental abilities and that results in bodily injury or a substantial risk of immediate harm to the child;

(b) failing to seek, obtain, or follow through with medical care for a child, with the failure resulting in or presenting a substantial risk of death, disfigurement, or bodily injury or with the failure resulting in an observable and material impairment to the growth, development, or functioning of the child;

(c) the failure to provide a child with food, clothing, or shelter necessary to sustain the life or health of the child, excluding failure caused primarily by financial inability unless relief services had been offered and refused;

(d) placing a child in or failing to remove the child from a situation in which the child would be exposed to a substantial risk of sexual conduct harmful to the child; or

(e) placing a child in or failing to remove the child from a situation in which the child would be exposed to acts or omissions that constitute abuse under Subdivision (1)(E),

$(\mathrm{F}),(\mathrm{G}),(\mathrm{H})$, or $(\mathrm{K})$ committed against another child;

(iii) the failure by the person responsible for a child's care, custody, or welfare to permit the child to return to the child's home without arranging for the necessary care for the child after the child has been absent from the home for any reason, including having been in residential placement or having run away; or

(iv) a negligent act or omission by an employee, volunteer, or other individual working under the auspices of a facility or program, including failure to comply with an individual treatment plan, plan of care, or individualized service plan, that causes or may cause substantial emotional harm or physical injury to, or the death of, a child served by the facility or program as further described by rule or policy; and

(B) does not include the refusal by a person responsible for a child's care, custody, or welfare to permit the child to remain in or return to the child's home resulting in the placement of the child in the conservatorship of the department if:

(i) the child has a severe emotional disturbance;

(ii) the person's refusal is based solely on the person's inability to obtain mental health services necessary to protect the safety and well-being of the child; and

(iii) the person has exhausted all reasonable means available to the person to obtain the mental health services described by Subparagraph (ii). (Government of Texas, 2019) 
Florida. In Florida, the number of reported 'neglect only' cases is about $40.1 \%$ of all of their cases. This totals to 14,751 cases (USDHHS), 2019). This number may seem much smaller than California and Texas; however, when these numbers are compared with Florida's population of 4.1 million children (U.S. Census Bureau, 2019), it is comparatively higher. Specifically, in Florida, approximately $2.76 \%$ of children each year will be involved with the Department of Children services for neglect only reasons. Below is the official definition of neglect in Florida.

Definition of Neglect: (e) "Neglect of a child" means:

1. A caregiver's failure or omission to provide a child with the care, supervision, and services necessary to maintain the child's physical and mental health, including, but not limited to, food, nutrition, clothing, shelter, supervision, medicine, and medical services that a prudent person would consider essential for the well-being of the child; or

2. A caregiver's failure to make a reasonable effort to protect a child from abuse, neglect, or exploitation by another person.

Except as otherwise provided in this section, neglect of a child may be based on repeated conduct or on a single incident or omission that results in, or could reasonably be expected to result in, serious physical or mental injury, or a substantial risk of death, to a child (The Florida Legislature, 2020)

Hawaii. Hawaii reported only $2.7 \%$ of their maltreatment cases as neglect only. This translates to just 34 cases total. This is drastically different than the 44 other states whose numbers are reported in the thousands (U.S. Department of Health and Human Services, Administration for Children and Families, Administration on Children, Youth and Families,

Children's Bureau, 2019). The population of minors in Hawaii is around 84,952 (U.S. Census Bureau, 2019). This too, is much smaller than the previous high case states; however, relative averages of reported neglect only cases are about .04\% of children who are involved with child protectives services. Below is Hawaii's published definition of neglect and child abuse, which are defined together:

Child abuse or neglect is defined by Chapter 350, HRS as: ..."the acts or omissions of any person who, or legal entity which, is in any manner or degree related to the child, is residing with the child, or is otherwise responsible for the child's care, that have resulted in the physical or psychological health or welfare of the child, who is under the age of eighteen, to be harmed, or to be subject to any reasonably foreseeable, substantial risk of being harmed"... The acts or omissions that must be reported pursuant to Chapter 350, HRS includes, but is not limited to: 1 . When the child exhibits evidence of: A. Substantial or multiple skin bruising or any other internal bleeding; B. Any injury to skin causing substantial bleeding; C. Malnutrition; D. Failure to thrive; E. Burn or burns; F. Poisoning;

G. Fracture of any bone; H. Subdural hematoma; I. Soft tissue swelling; J. Extreme pain; K. Extreme mental distress; L. Gross degradation; 2 M. Death; and such injury is not justifiably explained, or when the history given concerning such condition or death is at variance with the degree or type of such condition or death, or circumstances indicate that such condition or death may not be the product of an accidental occurrence; or 2 . When the child has been the victim of sexual contact or conduct, including, but not limited to, rape, sodomy, molestation, sexual fondling, incest, or prostitution; obscene or pornographic photographing, or filming, or depiction; or other similar forms of sexual exploitation, or 3. When there exists injury to the psychological capacity of a child as is evidenced by an observable and substantial impairment in the child's ability to function; or 4 . When the child is not provided in a timely manner with adequate food, clothing, shelter, psychological care, physical care, medical care, or supervision; or 5. When the child is provided with dangerous, harmful, or detrimental drugs as defined by section 712-1240; provided that this paragraph shall not apply when such drugs are provided to the child pursuant to the direction or prescription of a practitioner (State of Hawaii Department of Human Services 2017).

Vermont. Vermont reported the lowest number of neglect cases of all the 50 states. There were only 5 neglect only cases reported in 2018 , constituting $.5 \%$ of all their maltreatment cases. The main cause for concern was physical abuse which was significantly higher at 530 cases (USDHHS), 2019). The minor population is approximately 112,318 (U.S. Census Bureau, 2019) resulting in an annual average of $.04 \%$ of the children who will likely be involved with the Department of Children and Families. Vermont defines neglect as: "The failure to supply a child with adequate food, clothing, shelter or health care, including medical or non-medical remedial health care permitted or authorized under state law (33 VSA $§ 4912(6)(B)$ )" (Vermont Agency of Human Services Department for Children and Families, 2019).

Comparing and Contrasting Definitions of Neglect

\subsection{Literature Review: Interpretation of Selected States' Definitions and Reported Incidences of Child Neglect}

The purpose of a Child Protective Services worker (CPSW) is to assess a child's safety in a home and determine if intervention is necessary (Milani, et al., 2020). In order to achieve this purpose, there are two tools needed. First, a clearly defined statute as a guide is needed so the CPSW can make a clear determination using sound judgment. The states that have a high amount of child 


\section{How the Lack of a Universal Definition of Childhood Neglect is Negatively Impacting U.S. Families}

welfare cases for "neglect only" such as California, Texas, and Florida all contain aspects of the definition of neglect that are left to be interpreted by the investigator. Florida and California have very similar definitions according to how they both list some occurrences that constitute neglect such as not providing adequate food, shelter or medical services. However, they also state that neglect is not limited to those omissions (food, shelter or medical services). This means that it is up to the investigator to determine what may be appropriate or appear risky when determining if neglect is occurring. Some shared key aspects of language that allow room for interpretation in Florida and California's definitions are "The failure or inability of the parent or guardian to adequately supervise or protect the child" or "there is substantial risk that child may suffer harm." This is an important distinction because the child may have never been harmed; however, the investigator may feel that the child is at risk and deem it so. There aren't any specific guidelines as to what makes a child "at risk." Texas's definition of neglect is very extensive; however, most of it is nonspecific and leaves the determination up to the investigator to presume what they feel like could happen to a child. For example, the Texas's definition states that the following is an example of neglect: "the leaving of a child in a situation where the child would be exposed to a substantial risk" and "placing a child in or failing to remove a child from a situation that a reasonable person would realize requires judgment." While those statements appear valid, what one investigator might ascertain as risky may differ from what another investigator may consider risky.

Hawaii's definition of neglect is both extensive and specific. The definition explains how essential it is for children to not be involved in situations that are risky, but it specifically outlines what must be visible in order for situations to be identified as such (i.e., evidence of mental distress or physical harm such as bruising, burns, or fractured bones that cannot be explained by any other injury). Vermont's definition of neglect is the shortest of all, but it is extremely specific. Both of these states have low amounts of 'neglect only' cases and have specific definitions. Hawaii and Vermont have also vowed to not unnecessarily remove children from their homes. In Hawaii, the Department of Human Services has created a Crisis Response team whose fundamental guiding principle is to keep children in their homes, safely, whenever possible (State of Hawaii Department of Human Services, 2017). The county commissioner of Vermont, Ken Schatz, stated the following:

Through all of this, we hope to decrease the number of children in DCF custody and safely keep more children in their homes or with relatives. We will continue our efforts to support parents who are struggling with substance use, housing instability and mental health concerns by connecting them with services to help them stabilize (Vermont Agency of Human Services Department for Children and Families, 2019).

\section{THEORETICAL PERSPECTIVE}

\subsection{The Premise of Social Judgment Theory}

Social Judgment Theory has been used in many important applications like policy capturing which investigates decision-making in evaluative judgments, as well as research into insight, learning, dynamic decision-making and the investigation of values (Doherty $\&$ Kurz, 1996). Social Judgment Theory was developed in the 1960s as a way to explain how individuals process information from their environment and their interactions with others to form and change opinions. The premise of this theory is that there is a judgmental process involved in decision- making (Chau, Wong, Chow, \& Fung, 2014). A person's attitude encompasses three different zones: latitude of acceptance (acceptable opinions), latitude of rejection (unacceptable opinions), and latitude of noncommitment (opinions that haven't been committed to). During the judgmental process, a person compares their previously held opinions with the newly presented opinions and assigns them to one of the three different latitude categories (Aghbolagh, Zamani, Paolini, \& Chen, 2020). A person's standpoint is their current perspective on any particular subject. It is usually predicated on their own personal experiences, values, and belief system.

When a new opinion is presented and is near a person's standpoint, it becomes acceptable and enters their latitude of acceptance. Conversely, if the presented opinion is far from their standpoint, it is unacceptable and enters their latitude of rejection. If the opinion is neither near nor far from the individual's standpoint, then the person does not change or form a new opinion and it falls within their latitude of noncommitment. The assignment to the zones of latitude is an individualized process as it based on a person's individual level of tolerance, experiences, ego and level of familiarity with the topic being considered (Chau, Wong, Chow, \& Fung, 2014). If a person has a low level of tolerance and/or a large ego, many opinions may fall within their latitude of rejection. A person with little experience or level of familiarity with a topic, may not be equipped to properly assess new opinions and may arbitrarily place these new opinions in any zone. Opinions can be presented in direct and indirect ways. Direct presentations of opinions can be delivered via personal statements or conversations. Indirect presentations of opinions can be derived through observations of both action and inaction. As people enter new environments or engage in conversations with others, there is a constant judgmental process occurring as we take in new information and formulate opinions. These formations of opinions become an integral aspect of decision making. 


\section{How the Lack of a Universal Definition of Childhood Neglect is Negatively Impacting U.S. Families}

\subsection{Synthesis: Theory and Application}

According to Ray Cooksey, understanding problems that may arise with judgment involves a breakdown of three components. The first component is to decipher what is the judgment task in the ecology of the situation. In the case of child welfare, the ecology is the home of the child and the task is to determine if a child has been neglected or abused. The second component is to determine who the judges are. With this component, the child protective investigators are the judges because they are responsible for investigating and making a decision about the safety of a child. The third component is to consider the values associated with the task, not only of the judge and what is important to them, but also who is being affected by the judge's decision (Cooksey, 1996). In this context, what is important to each individual investigator may vary. This variance in values can impact families in different ways.

When an investigator enters a home, they will be presented with cues from the environment as well as opinions from the parents as they complete their interview. If the cues from the environment or the opinions from the parents align with the investigator's latitude of acceptance, there is a higher chance that the investigator will deem the child as safe. Contrariwise, if the cues or opinions fall within the latitude of rejection, then this increases the likelihood a case will be opened and the child may be removed. Thus, it becomes imperative to understand how latitudes affect investigators' judgments. Child protective workers are typically obligated to make a decision about child removal quickly without adequate time to gather enough information and to properly assess family situations. This means that they rely on their judgment, a judgment that can be biased, which can lead to unnecessary removals.

In a study conducted by Milani et al, (2020) the decision-making ecology model demonstrated how case workers may make quick decisions based on belief systems about stereotypes, gender, poverty and other risk factors they encounter. In their case study of 340 families, the study's authors were able to determine which factors put families at risk for a determination to remove a child from their home by the case worker. These risk factors varied based on whether the family was headed by a single mother, single father, or by two parents. Using a decision tree model the researchers were able to pinpoint different predictors that were likely to result in child removal. For single mothers, there were eight predictors that signaled child removal, which represented the highest number of predictors for any household type. Predictors included factors such as unwanted maternity, substance abuse, autonomy and lack of knowledge about child development. In the cases with single fathers, there were only five predictors found for child removal. These predictors were different than the single mother predictors. The CPS workers considered the fathers' self-esteem, having a close relationship with at least one family member, and chronic poverty. There were also five predictors of removal for two-parents households which included the parents' desires to improve themselves, disregard for child development, and low educational achievement (Milani et al , 2020). These results demonstrate how the CPS worker's decisions are not solely based on children's well-being, but rather upon the case worker's subjective perceptions of parenting abilities. This is significant because it also reveals how case workers place different weights on different aspects of parenting depending on the structure of the household. As a result, a child may be more likely to be removed from a single mother, than a single father or from a two-parent household, not for reasons of their environment but by reasons of case workers' judgments on household types.

Another study completed by Haan et al. (2019) also looked at the varying factors that may impact a child protective investigator's decision to remove a child for the home. This study looked at six different characteristics of each child welfare professional: work experience, general attitude towards effectiveness of child removals, general attitude on the harms of child removal, dispositional mindset that parents cannot change, and parent-specific mindset that parents can change. Each of the professionals in the study were given anonymous case reports and were asked to make a determination based on the information provided if they would remove the child or keep the child with their family. The professionals that were the least likely to make the determination for removal had with the following two characteristics: 1) the belief that child removals were harmful, and 2) a flexible parent-specific mindset that parents can improve their parenting. The professionals that were mostly likely to make the decision to remove the children had the following two characteristics: 1) they did not believe child removals to be very harmful, and 2) had a fixed dispositional mindset that parents would not change their parenting. Neither work experience nor professional background showed any correlational association with any decision to remove a child or to keep the child with their families. Again, these results revealed that the case worker's personal beliefs were the most influential on their judgment to remove a child.

\section{DISCUSSION}

The research on the harms of removing children from their homes is rich and continues to grow. These bodies of research base their findings on theories grounded in trauma informed care, resilience, ACES, and positive development. There are fewer bodies of research that reveal how Child Protective Service Workers may be biased, seemingly working against families in poverty and of color discriminately. No research studies to date have used social judgment theory to explain how child protective investigators make decisions regarding child welfare when they are reliant on their own interpretations. Because investigators in many states have not been provided with a specific statute that clarifies the physical and psychological indicators of neglect, they are often left to use their own determination and best judgment to assess the situation based on personal beliefs. Unfortunately, their judgments are often clouded by personal bias. 


\section{How the Lack of a Universal Definition of Childhood Neglect is Negatively Impacting U.S. Families}

Despite the abundance of research advocating that there is a better way to help families, there are only two states, Vermont and Hawaii, that have made positive changes to their policy and, therefore, have dramatically reduced the number of children in the Child Welfare system. Vermont and Hawaii have two commonalities, they both have vowed to keep children safely at home when possible and both have very specific statutes for their case workers to follow. A universal definition of child neglect among all states which models that of either Vermont or Hawaii may be the gateway that prevents subjective bias and judgment, as well as be a catalyst for true child welfare reform. Additionally, social judgment theory can be used as a helpful tool for policymakers to better understand how making informed judgments are critical to decisionmaking regarding the determination of neglect and the need for child removal. Clearly, a specific definition of neglect may work to limit any unfounded decisions that can be destructive to children and families. A universal definition may also help to ensure that all families have more unbiased opportunities to experience judgment-free rulings for their family.

\section{CONCLUSION}

A compare and contrast approach to analyze the correlations between states' definitions of child neglect and the amount of child neglect cases may hold the answer as to why there is such discrepancy in child neglect cases across the country. The current vagueness of some states' definitions allows for judgment on the part of child welfare professionals to make child removal decisions based on personal attitudes and beliefs. Social judgment theory can be used to demonstrate how child protective services workers form opinions about families and subsequently make the decision to remove children from the home. The importance of understanding how sound or unsound judgments from the child protective services workers may affect the welfare of a family is critical to well-being.

\section{REFERENCES}

1) U.S. Department of Health and Human Services, Administration for Children and Families, Administrationon Children, Youth and Families, Children's Bureau. (2019, August 22).

2) Adoption and Foster Care Analysis and Reporting System (AFCARS) FY 2018 data. Retrieved March 25, 2020, from https://www.acf.hhs.gov/cb

3) Aghbolagh, H. D., Zamani, M., Paolini, S., \& Chen, Z. (2020). Balance seeking opinion dynamics model based on social judgment theory. Physica D: Nonlinear Phenomena, 403, 132336. doi: 10.1016/j.physd.2020.132336

4) Chau, H., Wong, C., Chow, F., \& Fung, C.-H. F. (2014). Social judgment theory based model on opinion formation, polarization and evolution. Physica A: Statistical Mechanics and Its Applications, 415, 133-140. doi: 10.1016/j.physa.2014.07.082

5) Children's Bureau Child Welfare Information Gateway. (2019, March). State Statutes Search. Retrieved March 26, 2020, from

https://www.childwelfare.gov/topics/systemwide/lawspolicies/state/?CWIGFunctionsaction=statestatutes:main.getResults

6) Cooksey, R. W. (1996). The Methodology of Social Judgment Theory. Thinking \& Reasoning, 2(2-3), 141-174. doi: $10.1080 / 135467896394483$

7) Doherty, M. E., \& Kurz, E. M. (1996). Social Judgment Theory. Thinking \& Reasoning, 2(2-3), 109-140. doi: $10.1080 / 135467896394474$

8) Government of Texas. (2019, November). FAMILY CODE TITLE 5. THE PARENT-CHILD RELATIONSHIP AND THE SUIT AFFECTING THE PARENT-CHILD RELATIONSHIP SUBTITLE E. PROTECTION OF THE CHILD CHAPTER 261. INVESTIGATION OF REPORT OF CHILD ABUSE OR NEGLECT SUBCHAPTER A. GENERAL PROVISIONS. Retrieved March 26, 2020, from https://statutes.capitol.texas.gov/Docs/FA/htm/FA.261.html

9) Haan, W. D. D., Berkel, S. R. V., Asdonk, S. V. D., Finkenauer, C., Forder, C. J., Ijzendoorn, M. H. V., ... Alink, L. R. A. (2019). Out-of-home placement decisions: How individual characteristics of professionals are reflected in deciding about child protection cases. Developmental Child Welfare, 1(4), 312-326. doi: 10.1177/2516103219887974

10) Milani, L., Grumi, S., Camisasca, E., Miragoli, S., Traficante, D., \& Blasio, P. D. (2020). Familial risk and protective factors affecting CPS professionals' child removal decision: A decision tree analysis study. Children and Youth Services Review, 109, 104687. doi: 10.1016/j.childyouth.2019.104687

11) State of Hawaii Department of Human Services. (n.d.). Child Abuse and Neglect Reports. Retrieved March 26, 2020, from http://humanservices.hawaii.gov/reports/child-abuse-andneglect-reports/

12) The Florida Legislature. (2020, March 26). The 2019 Florida Statutes. Retrieved from http://www.leg.state.fl.us/Statutes/index.cfm?App_mode=Display_Statute\&URL=08000899/0827/Sections/0827.03.html

13) U.S. Cenus Burea. (2019, July). U.S. Census Bureau QuickFacts. Retrieved March 26, 2020, from https://www.census.gov/quickfacts

14) Vermont Agency of Human Services Department for Children and Families. (2019, March 1). FSD Policies. Retrieved from https://dcf.vermont.gov/fsd/policies 